ГORIGINAL ARTICLE-

Volume 13 Issue 22021

DOI: 10.21315/eimj2021.13.2.5

ARTICLE INFO

Received: 11-03-2021

Accepted: 23-04-2021

Online: 30-06-2021

\section{Perceptions of Mentors and Mentees towards the Mentoring System at the Universiti Kebangsaan Malaysia Medical Centre}

\author{
Mohammad Arif Kamarudin', Shah-Abas Muhamad Md Shah', \\ Noor Aisyah Somkam Ismail', Teh Pui Yen', Aini Syahirah Shamsul', \\ Hasnurul Idayu Che Razali', Abdus Salam² \\ ${ }^{1}$ Department of Medical Education, Faculty of Medicine, Universiti \\ Kebangsaan Malaysia Medical Centre, Kuala Lumpur, MALAYSIA \\ ${ }^{2}$ Medical Education Unit, Faculty of Medicine, Widad University \\ College, Kuantan, MALAYSIA
}

To cite this article: Kamarudin MA, Md Shah S-AM, Ismail NAS, Yen TP, Shamsul AS, Che Razali HI, Salam A. Perceptions of mentors and mentees towards the mentoring system at the Universiti Kebangsaan Malaysia Medical Centre. Education in Medicine Journal. 2021;13(2):55-70. https://doi.org/10.21315/eimj2021.13.2.5

To link to this article: https://doi.org/10.21315/eimj2021.13.2.5

\title{
ABSTRACT
}

Mentoring is a relationship between mentors and mentees focused on the career success and advancement of mentees. It is crucial to review and evaluate the mentoring system in place in any given institution to identify potential issues. This study aimed to ascertain the perception of mentors and mentees towards mentoring system at Universiti Kebangsaan Malaysia Medical Centre (UKMMC). This cross-sectional study involved 382 UKMMC medical students from Year-2 to Year-5, and 35 UKMMC lecturers. Data were collected by sending validated questionnaires through Google Forms to all 819 students via the Facebook groups of UKM medical students. The questionnaires for mentors were distributed to all 78 lecturers through their respective emails. Both mentors and mentees showed positive perceptions towards the mentoring system with a total score of 110/144 (76\%) and 51/64 (80\%), respectively. Year-2 and Year-3 mentees showed higher perception compared to Year-4. Mentees supervised under pre-clinical mentors and female mentors had higher perceptions compared to clinical mentors and male mentors. Respondents reported suggestions for improving the content and structure of the mentoring system, the need for additional training of mentors (especially on how to approach the mentees), retaining the same mentors and mentees pairing throughout the mentees' education, and reviewing the assessment method. The study findings may help further in improving the mentoring system of UKMMC. Mentoring is a challenging task. Medical schools must assign mentoring due importance in regular training for all levels of mentors by welltrained trainers. The implementation of awards and incentives for institutional mentors may motivate them further.

Keywords: Mentor-Mentee, Perceptions, Mentoring system, UKM undergraduate medical education 


\section{INTRODUCTION}

The original concept of mentorship can be traced back to a story in Greek mythology in which Odysseus, preparing for a journey to the Trojan War, left his son Telemachus under the supervision of Mentor, his trusted friend. Mentor was accountable for Telemachus' education as well as moulding his character and developing his wisdom and commitment to his purpose (1). Stemming from this legend, the term "mentor" began to be used to describe a trusted, senior advisor who guides a more junior person. The Standing Committee on Postgraduate Medical and Dental Education (SCOPME) has defined mentorship as "a process whereby an experienced, highly regarded, an empathic person (the mentor) guides another individual (the mentee) in the development and examination of their ideas, learning and personal and professional development" (2).

The modern concept of mentorship was originally developed in large privatesector corporations in the early 1970 s and was later introduced into the medical profession in the 1990s. Formal mentoring programmes for medical students and doctors, however, have only been widely practiced within the last 20 years (3). In the past, mentoring within medicine was an informal process occurring spontaneously between junior doctors and their seniors. The shift towards formal mentorship can be attributed to the increased clinical, research, and administrative demands on medical professionals and the modernisation of medical career pathways that limit the opportunity for the spontaneous establishment of mentormentee relationships (4). Formal mentoring is considered a core duty of medical faculty in the successful fulfillment of its academic mission. The components in the mentoring system include a mentor, a mentee, setting objectives, and the development of a mutual relationship for the personal development of mentees (5). Formal mentoring is challenging to develop and carry out, as it requires a strict selection and training process, formal agreements, a curriculum with clear rules and responsibilities, goals and expectations, and scheduled reviews (6). Mentors need to understand their role and have the knowledge and skills to help mentees professionally (7).

The success of mentorship programme is difficult to evaluate, as no standardised measure of success has been established. Many studies considered a programme to be successful based on the mentors' and mentees' positive perceptions of the programme $(3,6,8)$. Failures in mentoring, such as low quality of the relationship, dominance of the mentor, and blurred lines for intellectual property between the mentor and mentee have been reported (9). This can be attributed to the artificial relationship between the mentor and mentee. The causes for these artificial experiences are multidimensional such as lack of trust, bad intent from the side of the mentee, dysfunctional behaviour of the mentor due to lack of training, or their inability to adapt to the changing needs of their mentee (10). As the process of establishing and maintaining the mentor-mentee relationship is different in every mentorship programme, it is crucial for a mentoring system in any given institution to be evaluated to identify any issues which may arise.

The mentoring programme at the Universiti Kebangsaan Malaysia Medical Centre (UKMMC) has run for almost nine years under the personal and professional development (PPD) module. It is aimed at nurturing and equipping the students with the general skills essential for a medical doctor. The main role of mentoring system in UKMMC is to promote and assist students in personal and professional development. Mentors play an important role as role models to their mentees, in the hope of turning the medical students into benevolence medical practitioners. The mentoring programme is a one-toone relationship between a student and a lecturer. Each mentor is limited to four to five mentees. Mentors are either assigned to 
or chosen by mentees voluntarily each year. However, mentees can choose to retain or change mentors for a new semester. The new and current mentors involved in the mentoring system are given briefing sessions and attend workshops before the beginning of the first semester of the year.

Compulsory structured meeting sessions are held two times a year for Year-2 to Year-4 and include introductory meetings and formative (second) meetings. Year-5 medical students meet with their mentors three times a year, including an introductory meeting, progress meeting and formative meeting. During each meeting, the mentor discusses the students' portfolio, assess their personal and professional conducts, and provides constructive feedback and extra support if required. The portfolio is a framework comprising evidence of achievement of learning outcomes over time. It includes the student's curriculum vitae, self-assessment of personal and professional conduct, peer assessment, mentor assessment, certificates of attendance or any award, logbooks, end-semesters examination results. It also includes the student's strengths, weaknesses, opportunities, and threats (SWOT) analysis, and reflective writing assignment. SWOT analysis helps them to determine a clear picture of themselves and enables them to achieve the goal. Reflective writing allows the learners to think critically about their experiences and to learn from their experiences. Topics for the reflective writing are centred on their experiences as students in the clinical years, what they have learned from such experiences, and how these experience have made them better and helped them to become medical doctors in the future. Finalyear students add the additional reports of the performance of clerkship postings and patient feedback.

The assessment of the mentees is done by mentors in the formative meetings of the year. For Year-2 students, the assessment is formative. Their mentors discuss the mentees' academic and daily lives that included the mentees' relationship with their friends, financial issues and so on. For Year-3 to Year-5 students, the assessment is both formative and summative. By using a checklist, students are assessed in terms of attributes such as honesty, accountability, responsibility, etc. They are also assessed based on their reflective writings and SWOT analysis.

Although mentorship has long been established in UKMMC, no research has been done to ascertain the perceptions of mentors-mentees. This study aims to evaluate the perceptions of mentors and mentees towards the mentoring system at UKMMC. This study may provide useful information for an internal review and assessment of the system, as well as findings may also help other teaching institutes in the planning, implementation, evaluation and improvement of mentoring system.

\section{MATERIALS AND METHODS}

This study employed a cross-sectional questionnaire survey conducted in 2018 at UKMMC, involving medical students from Year-2 to Year-5 and lecturers involved as mentors for undergraduate students. The study was approved by the Research and Ethics Committee of UKM with project code: FF 2018-232. The study populations included 819 medical students from Faculty of Medicine as well as from the twin programme students of UKMUNPAD (Universitas Padjadjaran) twin and UKM-Allianze University College of Medical Sciences (AUCMS) twin, as well as 78 lecturers from Faculty of Medicine. In the present study, mentees' feedback was based on their perception of their current mentor involved with the mentoring. The sample included 382 medical students and 35 lecturers. The convenience sampling method was used to select the samples.

The UKM-UNPAD twinning programme is a Medical Doctor Programme in which students spend three years studying basic sciences at UNPAD, Bandung, Indonesia, and another three years for 
their clinical-sciences studies at UKM, Cheras, Malaysia. Graduates from this programme are conferred with two degrees: Sarjana Kedokteran (UNPAD) and Doctor of Medicine (UKM). The UKMAUCMS twinning programme is a five year programme that offers a Doctor of Medicine - UKM degree after completion of five years of study. This programme consists of two phases where the first phase consists of two years of pre-clinical studies completed at AUCMS Pulau Pinang by using the same UKM curriculum. The second phase is the three years of clinical study under UKM, completed at Ministry of Health affiliated hospitals. The UKM-AUCMS twinning programme has been discontinued.

The medical student selection at Faculty of Medicine is done by the multiple mini interview method since 2017. During the interview, candidates are required to respond to five different scenarios to assess their specific attributes while moving through five stations, with each station lead with a different interviewer. The tuition fee for students under the public quota for Doctor of Medicine (MD)-UKM programme is around RM13,600 while the fee for the UKM-twinning programme is higher, commensurate with that of private universities.

The study instruments included two separate questionnaires designed to evaluate the perceptions of the mentees and the mentors about the mentoring system, its impacts and ways to improve. The questionnaire for the mentees was developed based on the literature review $(3,11,12)$ while the questionnaire for the mentors was modified and adapted from a previous study (13). Before conducting the actual study, both questionnaires were validated through a pilot study on participants who were excluded from this study. The internal consistency of the questionnaires both for mentees and mentors were good, with Cronbach's alpha scores of 0.815 and 0.810 , respectively.
The questionnaire for the mentees had five components. Component I includes the demography of the mentees. Component II included 12 items concerning the current status and issues of the mentoring system such as the relationship with the mentor, and receiving support, motivation and constructive feedback from the mentor about the mentoring session. Component III included 12 items asking about the effects and impacts of the mentoring system towards mentees, such as communication skills, guidance on academic and nonacademic issues, and their satisfaction with their mentors and the mentoring system. Component IV included 12 items concerning ways to improve the mentoring system, such as mentor training, meeting frequency, mentor-mentee ratio, contents, and the structure of mentoring. The last component was the open comment segment for the mentees. A 4-point Likert scale was used to rate the items in each of the Components II, III and IV ranging from " 1 " (strongly disagree) to " 4 " (strongly agree). The highest score for the mentees in each of Components II, III and IV was 48 , and the total score was 144 .

The questionnaire for the mentors included four components and a 4-point Likert scale used to rate the items in the components, as in the mentees questionnaire. Component I included the demography including gender, race, mentoring, mentorship experience, pre-clinical or clinical position, etc. Component II included five items on the current status and issues of the mentoring system, such as the perception of the mentors about the training, their responsibilities towards mentees, frequency and time spend, communication with mentees, and satisfaction. Component III included 11 items to describe the effects and impacts of the mentoring system towards mentors such as perception about mentor's personal and professional development, the effects on their teaching, satisfaction, and preparedness to serve as a mentor in the 
future. The total score in Component II was 20 and the total score in Component III was 44 , for a total score of 64 . The last component contained optional narrative comment sections on ways to improve the mentoring system.

To collect the data, the mentees' questionnaires were administered to all 819 students using the Google Forms to all students via the Facebook groups of UKM medical students, while the questionnaires for mentors were distributed to all 78 lecturers through their respective emails. The survey was conducted in the English language. The objectives of the study were described at the beginning of the questionnaire and consent was taken from the participants. To prevent duplication of responses and participation in the study, medical students were required to provide their student identification number upon completing the questionnaire.

The data were compiled and analysed using SPSS Version 22. Sociodemographic data of the participants were presented as frequencies and percentages. While evaluating the mentoring programme, the scores were determined presented as number and SD. Independent samples $t$-tests were performed for the normally distributed samples to compare any significant difference between gender, supervised under pre-clinical or clinical mentor and male or female mentor, while a one-way ANOVA test was used in normally distributed samples for the year of study and university. For the samples which were not normally distributed, the non-parametric Mann-Whitney U test was used for gender, and supervision under pre-clinical or clinical mentor and male or female mentor, while the Kruskal-Wallis test was used for year of study and university. The significance level was at $P<0.05$. For qualitative analysis, free-text items were analysed and thematically categorised.

\section{RESULTS}

Out of 819 students, 382 responded, for a response rate of $47 \%$. Out of 78 lecturers, 35 responded, giving a response rate of $45 \%$. Table 1 showed the demography of the mentors and mentees. The majority of the student-respondents were female (75.65\%) and Malay (68.59\%). The UKM students and Year-4 students were the highest at $74.08 \%$ and $29.84 \%$, respectively. Similarly, female and Malay mentors predominate, and $57.14 \%$ of them had the experience of being a mentor for more than five years. Most of the mentors were from a clinical discipline.

Table 2 shows the distribution of mentees' perceptions of mentoring system. It was found that the samples were normally distributed except for Component III. The results showed that gender and university of mentee did not have any significant effects on perceptions of all Components II, III and IV of the mentoring system. However, there were significant differences based on the year of study in Component II. Multiple comparisons using Fisher's Least Significant Difference method showed Year-2 and Year-3 has significantly higher scores than Year-4. Mentees under pre-clinical mentor and mentees under female mentor showed a significantly higher score in Component II and Component III compared to mentees under clinical mentor and mentees under male mentors, respectively.

Table 3 shows the distribution of the mentors' perceptions of the mentoring system. There are no differences based on mentors' gender and mentor's pre-clinical or clinical position, and the year of the mentoring experience.

Table 4 shows the distribution of mentees' open comments for improvement of mentoring system. The comments were categorised as mentor preference, mentoring sessions, mentor-mentee ratio, content, mentors' training and satisfaction with mentors. 
Table 1: Socio demography of the participants

\begin{tabular}{|c|c|c|}
\hline Variables & Number & $\%$ \\
\hline \multicolumn{3}{|l|}{ Mentee $(n=382)$} \\
\hline \multicolumn{3}{|l|}{ Gender } \\
\hline Male & 93 & 24.35 \\
\hline Female & 289 & 75.65 \\
\hline \multicolumn{3}{|l|}{ Race } \\
\hline Malay & 262 & 68.59 \\
\hline Indian & 54 & 14.14 \\
\hline Chinese & 48 & 12.57 \\
\hline Others & 18 & 4.70 \\
\hline \multicolumn{3}{|l|}{ Year of study } \\
\hline Year-2 & 62 & 16.23 \\
\hline Year-3 & 113 & 29.58 \\
\hline Year-4 & 114 & 29.84 \\
\hline Year-5 & 93 & 24.35 \\
\hline \multicolumn{3}{|l|}{ University } \\
\hline UKM & 283 & 74.08 \\
\hline UKM-UNPAD twin & 64 & 16.75 \\
\hline UKM-AUCMS twin & 35 & 9.16 \\
\hline \multicolumn{3}{|l|}{ Supervised under } \\
\hline Pre-clinical lecturer & 178 & 46.60 \\
\hline Clinical lecturer & 204 & 53.40 \\
\hline Male mentor & 93 & 24.35 \\
\hline Female mentor & 289 & 75.65 \\
\hline \multicolumn{3}{|l|}{ Mentor $(n=35)$} \\
\hline \multicolumn{3}{|l|}{ Gender } \\
\hline Male & 8 & 22.86 \\
\hline Female & 27 & 77.14 \\
\hline \multicolumn{3}{|l|}{ Race } \\
\hline Malay & 27 & 77.14 \\
\hline Non-Malay & 8 & 22.86 \\
\hline \multicolumn{3}{|l|}{ Experience } \\
\hline $1-5$ years & 15 & 42.86 \\
\hline$>5$ years & 20 & 57.14 \\
\hline \multicolumn{3}{|l|}{ Mentor position } \\
\hline Pre-clinical & 11 & 31.43 \\
\hline Clinical & 24 & 68.57 \\
\hline
\end{tabular}

Table 5 shows the distribution of mentors' open comments on the UKM mentoring system. Five categories of opinions were identified such as mentor-mentee ratio, mentoring period, content, training, assessment and mentee.

\section{DISCUSSIONS}

\section{Perceptions towards Mentoring System}

Overall, both mentees and mentors in this study reported positive perceptions of the mentoring system of UKMMC with scores of $110.24 / 144(77 \%)$ and $51.11 / 64$ $(80 \%)$, respectively. In the mentees group, the highest score was obtained from the Component III, followed by Component II, while the reverse occurred in the mentors' group. A good score represents a good mentoring system with a good relationship between mentor and mentee which helps to achieve the objectives of mentoring.

The gender of the mentees had no significant impact on their perception of mentoring system. Therefore, we can say that both males and females can comfortably share their problems with mentors and both males and females go through the same stress and similar needs as a medical student at UKMMC. The previous study showed similar results, as gender led to no significant differences in the perception of the mentor-mentee system, indicating similar needs of all students irrespective of gender (12). There were also no differences in perceptions between mentees from the Faculty of Medicine, UKM-AUCMS twinning programme and UKM-UNPAD twinning programme. All programmes still go through the same study stressors and hardships as medical students. There was no bias between mentees' types of programmes and their mentors' behaviours. 


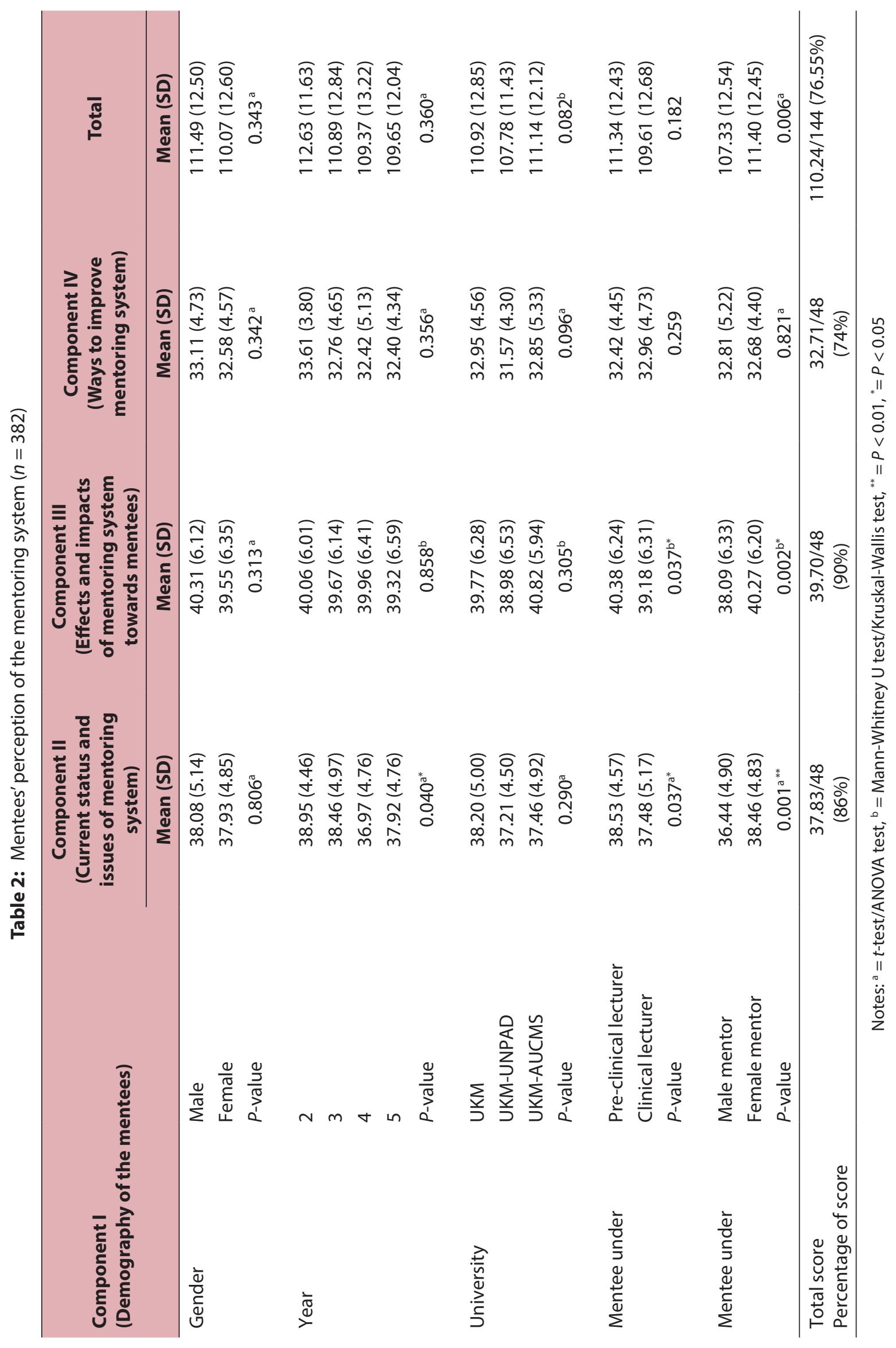


Table 3: Mentors' perception of mentoring system

\begin{tabular}{llccc}
\hline \multirow{2}{*}{ Component I } & & Component II & Component III & Total \\
\cline { 3 - 5 } & & Mean (SD) & Mean (SD) & Mean (SD) \\
\hline Gender & Male & $16.38(1.85)$ & $33.50(5.78)$ & $49.88(6.79)$ \\
& Female & $16.04(1.74)$ & $35.96(6.05)$ & $52(7.41)$ \\
& $P$-value & $0.637^{\mathrm{a}}$ & $0.315^{\mathrm{a}}$ & $0.474^{\mathrm{a}}$ \\
Mentor position & Pre-clinical & $16.45(1.50)$ & $34.91(7.62)$ & $51.36(8.87)$ \\
& Clinical & $15.95(1.85)$ & $35.62(5.27)$ & $51.58(6.57)$ \\
& $P$-value & $0.443^{\mathrm{a}}$ & $0.749^{\mathrm{a}}$ & $0.935^{\mathrm{a}}$ \\
Mentoring experience & $16(1.93)$ & $34.80(5.74)$ & $50.80(7.14)$ \\
& $1-5$ years & $16.20(1.64)$ & $34.85(6.29)$ & $52.05(7.43)$ \\
& $>5$ years & 0.743 & 0.616 & 0.620 \\
\hline Total score & $P$-value & $16.17 / 20$ & $34.94 / 44$ & $51.11 / 64$ \\
Percentage of score & & $(81 \%)$ & $(79 \%)$ & $(80 \%)$ \\
\hline
\end{tabular}

Note: $\mathrm{a}=t$-test/ANOVA test

Table 4: Mentees' open comments about the mentoring system

\begin{tabular}{ll}
\hline Category & Comments \\
\hline Mentor preference & Retain the same mentor throughout studying if possible. \\
& The mentor must be the same from the first year to the final year. \\
Same mentor in our clinical years until the end of final year. \\
Changing mentor every year is not effective for mentor-mentee bonding. \\
It is very hard and takes time for mentees to open up to their new mentors. \\
Mentoring sessions & More sessions with mentors. \\
& The group should meet more frequently. \\
& Frequent the meeting for a mentoring session in a year. \\
& Meeting should only be held according to the mentee's needs. \\
Mentor-mentee ratio & There are too many mentees under the same mentor. \\
It is better to have three to four mentees under the same mentor. & \\
An informal mentoring session is better. & Reduce reflective writing. \\
Try to avoid tasks during the mentoring sessions. \\
The content to be more diversified. \\
Should have an annual gathering with all mentors and mentees. \\
Have a friendly sports activity between mentoring groups. \\
Group outing with mentor and mentee. \\
Mentor need proper guidance on what to say. \\
Training on how to approach students.
\end{tabular}


Table 4 (Continued)

\begin{tabular}{ll}
\hline Category & Comments \\
\hline About mentor & I have a very nice mentor. \\
I am happy with my mentor. \\
I was lucky to get a good mentor who is very supportive. \\
It is a good session to have with mentors; continue this mentoring session. \\
Mentoring system in the Faculty of Medicine is good enough. \\
Sometimes no concrete advice and help is given. \\
It seems that meeting up with the mentor is just to fulfill the requirement. \\
Some of the mentors take this mentoring system lightly. \\
The mentor is very busy, it is quite hard to meet them.
\end{tabular}

Table 5: Mentors' open comments about the mentoring system

\begin{tabular}{|c|c|}
\hline Category & Comments \\
\hline \multirow[t]{3}{*}{ Mentor-mentee ratio } & $\begin{array}{l}\text { Reduce the number of mentees per mentor to improve the quality of the } \\
\text { relationship between the two parties. }\end{array}$ \\
\hline & The ideal number of mentees should be small e.g., four to five people. \\
\hline & Limit the number of students that a single mentor can take e.g., five mentees. \\
\hline \multirow[t]{3}{*}{ Mentoring period } & Students must be mentored for five consecutive years to keep the dynamic. \\
\hline & Great if Year-5 mentors have followed mentees from earlier years. \\
\hline & $\begin{array}{l}\text { It would be good to start assessing their PPD level either at the beginning of } \\
\text { Year-1 or Year-3 to produce a valid and reliable PPD level of the mentees. }\end{array}$ \\
\hline \multirow[t]{8}{*}{ Content } & More activities besides discussing the academy. \\
\hline & Have excursions outside camps. \\
\hline & Do away with reflective writing. \\
\hline & Should be less task-focused. \\
\hline & Things are too structured. \\
\hline & Reduce the number of structured meetings and assessments. \\
\hline & Replace the assessment with something more meaningful. \\
\hline & Reduce the paperwork. \\
\hline \multirow[t]{3}{*}{ Training } & Conduct workshop to increase the skills of the mentor. \\
\hline & Have more specific training yearly basis. \\
\hline & Standardise the training or level of mentors. \\
\hline \multirow[t]{4}{*}{ Assessment } & Assessment of our mentees needs further revision. \\
\hline & Should be assessed formatively without giving any marks to mentees. \\
\hline & $\begin{array}{l}\text { Review the student assessments, perhaps too detailed for short encounters } \\
\text { between mentor and mentees. }\end{array}$ \\
\hline & $\begin{array}{l}\text { The assessment form is more suitable for academic supervisors during clinical } \\
\text { posting. }\end{array}$ \\
\hline \multirow[t]{2}{*}{ Mentees } & Sometimes mentees seem not in need of mentoring. \\
\hline & $\begin{array}{l}\text { The current situation is more on the purpose to fulfil the requirement of the } \\
\text { faculty. Not so much of helping the student. }\end{array}$ \\
\hline
\end{tabular}


However, there was a significant difference noted on mentees' perception based on year of study, mentees supervised by pre-clinical or clinical mentors and mentees supervised by a male or female mentor. Year-2 and Year-3 mentees had a significantly higher score than Year-4 in Component II. A previous study has shown that Year-2 students rated higher in the perception of mentoring than final-year students (12), which is similar to our study findings, although no differences were noted with our final-year students. This represents higher satisfaction among Year-2 and Year-3 students. This may be due to the fact that Year-4 students face a higher burden with their clinical setting which the final-year students have usually overcome by that time, as they have become more familiar with the clinical environment. Interestingly, Year-3 students who are new in the clinical setting also scored higher compared to Year-4 students. Therefore, mentors need to pay special attention to identify and solve the problems faced by Year- 4 students.

Mentees supervised by pre-clinical mentors and female mentors showed higher scores than the mentees supervised by clinical mentor and by the male mentor in the Components II and III. A previous study by Lian et al. (12) also found that students under non-clinicians had higher perception than those under clinicians on the mentormentee system which is similar to this study. This may be due to the busy schedules of the clinical mentors making them less available for mentoring compared to the pre-clinical mentors. Therefore, mentees under pre-clinical mentors showed higher perceptions compared to mentees under the clinical mentor. In this study, female participants predominate both in the mentees' and mentors' groups. So, it is likely that same-sex mentor-mentee are more comfortable and make the mentoring more effective. It has been found that mentees benefit more from same-sex relationships concerning role modeling where mentee aspires to be like the mentor (14). Another study found that female mentors may provide more psychosocial mentoring, while male mentors may provide more career mentoring (15).

\section{The Effects and Impacts of Mentoring System on Mentees and Mentors}

UKMMC mentees participating in the mentoring system acknowledged a positive perception about the mentors and the presence of good mentoring relationships and communication between them. This mentoring helps them to improve their academic performance and meet their psychological needs. Their satisfaction with the mentors has also been expressed in their open comments. It is vital in the personal and professional development of the mentees as the context of positive relationships through the creation of trustworthy, nurturing environments can facilitate learning and the open expression of personal concerns. Only within these environments students can openly engage in identifying and addressing their core values, priorities and learning needs (16-17).

Mentees perceived that their communication skill improved after participating in the mentoring programme. Good communication skills are very important for the doctor as it can lead to overall patient satisfaction (18). It is the role of the mentor to guide and direct his or her mentees regarding the professional issues, encourage them in their ideas and works, and provide timely, clear and comprehensive feedback to mentees' questions. The mentoring relationship includes three dimensions of emotional and psychological support, assist with career and professional development, and role modeling (11). Mentees' perception of psychological support, as well as support in academic and non-academic issues, supports that the mentors' role was perfectly accomplished. As mentors are lecturers from UKMMC, they are most familiar with the medical curriculum and may provide appropriate academic advice to the mentees. In a good mentorship, mentors act as role models to 
their mentees through demonstration of the good characteristics of a compassionate doctor. This includes attentive listening, sharing time, being helpful and empathetic, as well as strong communication generally. Besides, there is a great possibility for a mentoring programme to become one way to teach medical students affective skills or achieving learning targets in the affective domain. Students who have experienced empathy and caring firsthand from their mentors may develop into more caring human beings and empathetic doctors (19). Thus, the mentoring system can be used as a way to achieve learning objectives in the affective domain.

Mentors also benefit from the mentoring system through personal and professional development as acknowledged in this study. This is in line with a past study by Stenfors-Hayes et al. (13) which showed that mentorship increased mentors' interest in teaching and provided a reflection of their values, teaching, and work practices. Mentors also reported that mentorship helped in improving their relationship with students. This is because the system provides opportunities and time for open communication with the medical students and thus, increasing mentors understanding regarding the way of thinking, situations, and feelings of the students. Subsequently, their awareness of and empathy towards students' problems increased.

Despite that, a few mentees also reported in the open comments that sometimes they do not receive any concrete advice and help, and that sometimes the meeting with the mentor seems just a fulfillment of the requirement. They also feel that some of the mentors take this mentoring system lightly, and in the busy schedule of the mentor, it is quite hard to meet them. As we know that mentors have busy schedules, it is important to motivate the mentors and to grow their interest in effective mentoring. In this regard, the importance of mentors training and other support for mentors such as financial incentives, reduction in academic load, recognition and nomination from the institution, should be considered (20).

\section{Mentoring Sessions}

Although the mentors were found to be generally very satisfied with the mentoring system, some mentors in this study identified some negative perceptions, such as "things were too structured" in the mentoring system. They suggested the meeting should be less task-focused and the number of structured meetings and assessments should be reduced as these would cause "rigid mentoring relationships". From the mentees' perspectives, they mentioned that as activities such as observing a student's academic performance, SWOT analysis, reflective writing, portfolio, family or personal relationships were repeated in every mentoring session for a few consecutive years, they feel bored and less engaged. Some mentors and mentees suggested a few possible activities such as sports activities or games, camping, excursions, as well as annual gatherings with all mentors and mentees. The rigid structure of the mentorship programme may be changed to a more flexible and mentee-driven mentoring session to provide an interesting and engaging experience for mentors and mentees alike. They suggest activities beyond academia as well as a reduction in paperwork.

Most of the mentors and mentees agreed that the time spent for a mentoring session was adequate; however, some suggested that meetings should be held more frequently during the semester. This is especially necessary for those who need extra meetings to get advice from the mentors on some academic or non-academic related difficulties. Therefore, in addition to the scheduled and structured mentoring sessions, there should be opportunities and flexibility for informal and spontaneous meetings to better meet the mentees' needs. Although the initiation for establishing a mentoring relationship is taken by mentors, 
i.e., top-down, it is the responsibility of the mentees to keep the relationship ongoing, i.e., bottom-up (21). Mentees are required to be proactive in seeking out their mentors according to their needs. Ideally, a motivated mentee should manage the work in the mentoring relationship by planning and setting the meeting agenda, asking questions, listening, completing assigned tasks and requesting feedback (22). This makes it easier for a mentor to help and guide a mentee, in turn making the relationship more satisfying and successful.

\section{Retaining the Same Mentor}

The importance of having the same mentors throughout studies was recognised by both mentors and mentees as this could allow better supervision of mentees. Some mentors had some difficulties in assessing their mentees as one mentor described that "some assessments are perhaps too detailed for the short encounters between mentor and mentees". Some mentors commented that "students must be mentored for five consecutive years to keep the dynamic" and this was important "to produce a valid and reliable PPD level of the mentees". Retaining the same mentor-mentees grouping or pairing could give mentors more opportunities for interaction, which allows them to assess their mentees more accurately and fairly.

From the mentees' perspectives, one mentee shared the experience of changing mentors every year which "is not effective for mentor-mentee bonding" and felt that "it is very hard and takes time for mentees to open up to their new mentors". There is no denying that retaining the same mentor throughout the mentees' course of studies will benefit the mentoring relationship. This is because mentoring is a complex activity that involves interpersonal "chemistry" between the mentor and mentee. Therefore, finding the right mentoring match is an important element in a successful mentoring programme (23). Similar to any other interpersonal relationship, the mentoring relationship evolves as both parties learn more about each other. A successful mentoring relationship may require solid benefits for the development and assessment of mentees. Hence, mentoring should be a no-fault relationship where, for good reason, either party has the option to terminate at any time without any risk or harm to their future and career (24). Every year, the mentoring system in UKMMC allowed students to apply and choose their preferred mentors. This flexible system gives the students the right to switch mentors if they are not comfortable with their current mentor.

\section{Number of Mentees Per Mentor}

The mentoring system usually limits the number of mentees to five students per mentor each year to avoid overburden and reduce scheduling difficulties. However, some mentors may take more than five mentees or more than one mentoring group from a different year, as they may be approached by too many students applying for mentorship. Therefore, the number of mentees in some of the mentor groups could be increased from five. In this study, some mentors and mentees suggested the number of mentees per mentoring group is reduced. As mentoring requires an investment of time, energy and emotional resources, the number of mentees should be standardised and limited to five students per mentor each year to avoid overburdening mentors, as well as to improve the quality of the mentoring relationship.

\section{Mentor Training}

In this present study, mentors emphasised specific standardised training workshops to increase the skills of mentors. However, surprisingly, a large number of mentees disagreed about the training need of their mentor as they believed that their mentors were adequately trained to lead the group. Nevertheless, in the open comments, some mentees expressed that it was essential to provide training for mentors, especially in 
terms of how to approach students. Several interpersonal skills are deemed necessary for an ideal mentor such as "motivate, empower and encourage, nurture self-confidence, teach by example, offer wise counsel and raise the performance bar" (25). However, these skills are not easily attained without experience and proper training. Mentor training helps mentors to engage in selfreflection and assessment and to develop the attitudes, personal qualities, knowledge and skills that are needed to maximise protégé success (26).

All mentors at UKMMC were required to attend a training workshop, which is conducted every year before the start of the programme. Mentor training workshops are organised through collaborations of the Department of Medical Education, Department of Psychiatry and Faculty of Education in UKMMC. Besides, mentoring meetings among mentors are organised two to three times every year to discuss any problems or issues encountered about mentorship. Some mentors in this study reported that additional training is necessary, as mentors must strive to constantly educate themselves to adapt to the educational needs of different mentees.

Faculty development plays a key role in sustaining academic vitality in medical education (27). Mentors and faculty generally are the scholarly assets of medical school (28), and to keep them updated and strong, regular training is necessary, irrespective of the position of mentors, as learning has no end and there is more to know and more to master (29). Adequate training may help mentors to foster an open, trustful and supportive learning climate to approach the mentees. Medical schools should give due importance to regular mentoring development training programmes across all levels of mentors by well-trained trainers aimed to produce a competent and confident graduate (30). Incentives or awards for mentors can be implemented by the institution to motivate and engage them, despite their busy schedules.

\section{LIMITATIONS OF THE STUDY}

Several limitations of this study should be noted. As a cross-sectional study, the data collected at a single point in time expresses only a snapshot of the perception of the population. It would be better if further data were collected at different periods to compare them with the present data. The survey results were measured using the Likert scale, which has limitations such as being unfavourable to allow respondent expression, a potential lack of accuracy in responses, biased responses, and so on. The small sample size is also limitation. Although the questionnaires allowed narrative remarks from the respondents, a greater depth of perceptions can be obtained through more rigorous qualitative research methods such as interviews or focus group discussions. This could lead to clarification of some issues that were not explored in this study, such as the perceived role of mentors and mentees, as well as the specific needs of mentees, particularly Year-4 students. A future study with higher numbers of respondents among mentors may also be considered.

\section{CONCLUSION}

This study concluded that most of the mentors (77\%) and mentees (80\%) have positive perceptions of the mentoring system of UKMMC. Gender and university did not influence the perception of mentees. Year-2 and Year-3 mentees showed higher perceptions compared to Year-4. Mentees supervised under pre-clinical mentors and female mentors have higher perceptions compared to those with clinical mentors and male mentors. Several proposed improvements to enhance the system were identified such as retaining the same mentor-mentee pairing through the duration of mentees' course, strictly ensure five mentees per group, more frequent meetings especially for those in need, ongoing mentor training, and assessing mentees formatively. Mentors should be 
chosen based on willingness and those who genuinely care about students and have adequate training on supportive learning climate that promotes how to approach the mentees. This study demonstrated that a successful mentoring system is important for both mentors and mentees as it appears to be beneficial for their development. Mentoring is a challenging task, and the implementation of mentor development programmes, especially in terms of how to approach the mentees, can play a key role in further development of the mentoring system in UKMMC. Medical schools should place due importance on regular training for all levels of mentors by a welltrained trainer. The implementation of awards and incentives for the mentors by the institution may also motivate them further.

\section{ACKNOWLEDGEMENTS}

The authors would like to thank UKMMC for providing the research grant (code: FF 2018-232) for this study. Thanks also to all students and teachers who participated in this study.

\section{REFERENCES}

1. Barondess JA. A brief history of mentoring. Trans Am Clin Climatol Assoc. 1995;106:124.

2. Oxley J, Standing Committee on Postgraduate Medical and Dental Education. Supporting doctors and dentists at work: an inquiry into mentoring. London: SCOPME; 1998.

3. Buddeberg-Fischer B, Herta KD. Formal mentoring programmes for medical students and doctors-a review of the Medline literature. Med Teach. 2006;28(3):248-57. https://doi.org/10.1080/01421590500313043
4. Warren OJ, Carnall R. Medical leadership: why it's important, what is required, and how we develop it. Postgrad Med J. 2011;87(1023):27-32. https://doi.org/10 $.1136 /$ pgmj.2009.093807

5. Mat Nor ZM, Yusoff MSB, Abdul Rahim FA. Characteristics of mentoring programmes in the early phase of medical training at the Universiti Sains Malaysia. J Taibah Univ Med Sci. 2017;12(4):343-8. https://doi.org/10.1016/ j.jtumed.2017.01.003

6. Henry-Noel N, Bishop M, Gwede CK, Petkova E, Szumacher E. Mentorship in medicine and other health professions. J Cancer Educ. 2019;34(4):629-37. https:/doi.org/10.1007/s13187-018-1360-6

7. Mat Nor MZ, Mohammad JAM, Yaacob NM. The USM mentoring inventory: a construct validity and reliability exercise. Education in Medicine Journal. 2019;11(2):15-26. https://doi.org/10.21315/ eimj2019.11.2.3

8. Sambunjak D, Straus SE, Marusic A. Mentoring in academic medicine: a systematic review. JAMA. 2006;296(9):1103-15. https://doi.org/10 $.1001 /$ jama.296.9.1103

9. Straus SE, Chatur F, Taylor M. Issues in the mentor-mentee relationship in academic medicine: a qualitative study. Acad Med. 2009;84(1):135-9. https://doi.org/10.1097/ ACM.0b013e31819301ab

10. Eby LT, Butts MM, Durley J, Ragins BR. Are bad experiences stronger than good ones in mentoring relationships? Evidence from the protégé and mentor perspective. J Vocat Behav. 2010;77(1):81-92. https:// doi.org/10.1016/j.jvb.2010.02.010

11. Berk R, Berg J, Mortimer R, Walton-Moss B, Yeo TP. Measuring the effectiveness of faculty mentoring relationships. Acad Med. 2005;80(1):66-71. https://doi.org/10 .1097/00001888-200501000-00017 
12. Lian CW, Ommar N, Fern JTS, Ismail S, Mohd Sharifudin TST, Hwan WS. Perception of the mentor-mentee system among medical students of the Faculty of Medicine and Health Sciences, Universiti Malaysia Sarawak. Education in Medicine Journal. 2013;5(2):e29-37. https://doi.org/ 10.5959/eimj.v5i2.41

13. Stenfors-Hayes T, Kalén S, Hult $H$, Dahlgren LO, Hindbeck $\mathrm{H}$, Ponzer S. Being a mentor for undergraduate medical students enhances personal and professional development. Med Teach. 2010;32(2):148-53. https://doi.org/10.3109/ 01421590903196995

14. Scandura TA, Williams EA. An investigation of the moderating effects of gender on the relationships between mentorship initiation and protégé perceptions of mentoring functions. Journal of Vocational Behavior. 2001;59(3):342-63. https://doi.org/10.1006/ jvbe.2001.1809

15. Allen TD, Eby LT. Factors related to mentor reports of mentoring functions provided: gender and relational characteristics. Sex Roles. 2004;50:129-39. https://doi.org/10.1023/ B:SERS.0000011078.48570.25

16. Sanfey H, Hollands C, Gantt NL. Strategies for building an effective mentoring relationship. Am J Surg. 2013;206(5):7148. https://doi.org/10.1016/j.amjsurg.2013.08 .001

17. Pololi L, Knight S. Mentoring faculty in academic medicine. A new paradigm? J Gen Intern Med. 2005;20:866-70. https:/doi .org/10.1111/j.1525-1497.2005.05007

18. Hausberg MC, Hergert A, Kröger C, Bullinger M, Rose M, Andreas S. Enhancing medical students' communication skills: development and evaluation of an undergraduate training program. BMC Med Educ. 2012;12:16. https://doi.org/10 $.1186 / 1472-6920-12-16$
19. Bhatia A, Singh N, Dhaliwal U. Mentoring for first-year medical students: humanising medical education. Indian J Med Ethics. 2013;10(2):100-3. https://doi.org/10.20529/ IJME.2013.030

20. Fallatah HI, Park YS, Farsi J, Tekian A. Mentoring clinical-year medical students: factors contributing to effective mentoring. J Med Educ Curric Dev. 2018;5:1-6. https://doi.org/10.1177/2382120518757717

21. Frei E, Stamm M, Buddeberg-Fischer B. Mentoring programs for medical students: a review of the PubMed literature 2000-2008. BMC Med Educ. 2010;10:32. https://doi .org/10.1186/1472-6920-10-32

22. Zerzan, JT, Hess R, Schur E, Phillips RS, Rigotti N. Making the most of mentors: a guide for mentees. Acad Med. 2009;84(1):140-4. https://doi.org/10.1097/ ACM.0b013e3181906e $8 \mathrm{f}$

23. Jackson VA, Palepu A, Szalacha L, Caswell C, Carr PL, Inui T. "Having the right chemistry": a qualitative study of mentoring in academic medicine. Acad Med. 2003;78(3):328-34. https://doi.org/10 .1097/00001888-200303000-00020

24. Straus SE, Johnson MO, Marquez C, Feldman MD. Characteristics of successful and failed mentoring relationships: a qualitative study across two academic health centers. Acad Med. 2013;88(1):82-9. https://doi.org/10.1097/ ACM.0b013e31827647a0

25. Souba, W. Mentoring young academic surgeons, our most precious asset. J Surg Res. 1999;82:113-20. https://doi.org/10.1006/ jsre.1999.5596

26. Geraci SA, Thigpen SC. A Review of mentoring in academic medicine. Am J Med Sci. 2017;353(2):151-7. https://doi.org/10 $.1016 /$ j.amjms.2016.12.002 
27. Amin Z, Eng KH, Seng CY, Hoon TC, Sun GP, Samarasekera MDD, Huak CY, Rhoon KD. A multi-institutional survey on faculty development needs, priorities and preferences in medical education in an Asian medical school. Med Educ Online. 2009;4:16. https://doi.org/10.3402/meo.v14i .4509

28. Salam A, Mohamad N, Siraj HH, Kamarudin MA, Yaman MN, Bujang SM. Team-based learning in a medical centre in Malaysia: perspectives of the faculty. The National Medical Journal of India. 2014;27(6):350.
29. Salam A. Challenges of problem-based learning. South East Asian Journal of Medical Education. 2009;3(2):54-60.

30. Salam A, Mohamad M. Teachers' perception on what makes teaching excellence: impact of faculty development programme. International Medical Journal. 2020;27(1):1-4. 